\title{
The Image of the Future of Russia: The View of Different Generations on Social Threats and Risks
}

\author{
Svetlana Turkulets ${ }^{1},{ }^{*}$ Aleksei Turkuletc ${ }^{1}$, Evgenia Listopadova $^{1}$, Irina Kalashnikova ${ }^{2}$ \\ ${ }^{1}$ Far Eastern State Transport University, Russia \\ ${ }^{2}$ Pacific National University, Russia \\ *Email: turswet@rambler.ru
}

\begin{abstract}
The purpose of the study is to identify the features of the opinion of representatives of three generations - X, Y and Z in determining the social risks caused by new external and internal threats, while constructing the image of the future of Russia.

The main methodological approach to the study of this topic is the activity approach, the essence of which is that the decisive role in modern societies is played by active social actors. In the course of the study, a scenario approach was used to determine the vectors of the future development of Russian society. The interdisciplinary nature of the research is dictated by the need to use specific empirical data, refer to the methodology of social philosophy, political science, and also take into account the peculiarities of socio-psychological analysis of the processes of personality identification. The empirical study was based on the theory of generations, developed by American scientists (Neil Howe and William Strauss) in the 20th century. The main empirical method was a questionnaire survey.

The novelty of the research consists in studying the public opinion of different generations about the future of Russia, taking into account risks and threats (in the representation of these generations), extrapolating the results of empirical research to the process of constructing the image of the future of Russia.

The scientific significance of the obtained results lies in the fact that by identifying the features of the world perception of the image of the future of Russia by different generations, it is possible to construct a generalized image that can become an integrating factor in the process of implementing the social activity of Russian citizens.

The applied significance of the results of the study is that they will help social scientists in their further theoretical research, designing forecasts and scenarios for the future of Russian society, and modern politicians - in developing programs of social reforms.
\end{abstract}

Keywords: The future of Russia, The Theory of Generations, Social risks, Threats.

\section{INTRODUCTION}

The desire for a better future is characteristic of every person, every society. The search for ways and means of improving social life took place at all stages of the development of human thought. Such studies are most active in times of crisis, revaluation of values, and loss of social ideals. At present, it seems necessary to construct an image of the future of Russia based on the study of social threats and risks that are obstacles to the formation of an optimal social state. However, it is necessary to take into account the differences in the perception of threats and risks by representatives of different generations, since they were socialized in conditions that are characteristic exclusively for a certain socio-historical period of development. In this regard, it is advisable to construct images of the future of Russia from the perspective of representatives of generations $\mathrm{X}, \mathrm{Y}$ and $\mathrm{Z}$, who are currently the most socially active part of the population.

\section{RESEARCH METHODS}

In the course of the research, the theoretical and empirical methods were used. At the initial stage, a bibliographic review and critical analysis of scientific 
works devoted to forecasting and designing the image of the future of Russia were conducted.

To conduct empirical research, the theory of generations, developed at the end of the twentieth century by American scientists, was applied, which by generation means people united by common values. Each period that defines a particular generation, according to this theory, lasts about 20 years. Currently, the most socially active people are people of generations $\mathrm{X}, \mathrm{Y}$ and $\mathrm{Z}$. Taking into account the specifics of the development of Russian society, we use the following gradation: generation X - 1963-1980, generation Y 1981-1995, generation Z - 1996-2003.

A sociological survey (questionnaire) was used as the main empirical method. The survey was conducted in an online format by sending invitations to the email addresses of students and teachers of Russian Far Eastern universities. 395 respondents took part in the survey. The survey results were processed using googl services and Microsoft Excel.

\section{STATEMENT OF THE PROBLEM}

Questions of the future of society are discussed today all over the world by scientists of different scientific fields. International conferences and symposia are regularly held, where sound social forecasts are presented, and future development scenarios are discussed [1]. Foreign scientists state an unsuccessful attempt of neoliberal social projects, which led to the aggravation of inequality, interethnic and interstate conflicts, depletion of resources, global warming, etc. [2]. It is noted that new information and communication technologies contribute to the acceleration of globalization. At the same time, according to the researchers, they are aimed not so much at integration and unification, but at separation, and contribute to preventing free exchange [3].

It is important that all forecasts and projects of the future, as a rule, are based on deep scientific research of new challenges and threats that the world in general and Russia in particular may face in the near future [4]. We can talk about a large number and variety of new social challenges, but, first of all, they relate to the sociocultural sphere, which has a significant impact on all other spheres of society's life. Thus, Russian scientists claim that ""reform experiments" in the field of education and science have led to the fact that the country is increasingly experiencing a shortage of qualified doctors, engineers, and scientists. In the near future, we will face a serious "challenge of ignorance"" [5, p.34]. Against this background, there is a deformation of channels and mechanisms for broadcasting cultural and spiritual heritage [6]. We are talking about what schooling, the media, other social institutions, first successfully carried out awarenessraising role of youth in shaping the general cultural erudition, in modern conditions of development of Russian society ceased to answer this purpose.

In addition, there are completely new challenges to human civilization. Among them is the worldwide spread of the COVID-19 pandemic, which has catastrophic and generally not yet fully realized humanitarian consequences [7].

At the same time, it is obvious that the perception of the significance of socio-cultural threats and risks differs among representatives of different generations. To construct an image of the future of Russia, it is necessary to analyze several "slices" of existing assessments of the current and future state of Russian society.

\section{RESEARCH RESULTS}

The empirical material used to illustrate theoretical propositions, generalizations and conclusions was obtained through a survey conducted as part of a project supported by the RFBR. The sample size was 395 people from among students and teachers of Russian Far Eastern universities. The survey in the context of the pandemic (November-December 2020) was conducted not in person, but with the help of Internet resources by distributing the questionnaire posted on the googl disk to the email addresses of students and teachers. The respondents were asked to indicate their year of birth in the questionnaire, and then answer questions related to the assessment of the current state of Russian society and its prospects.

The main hypothesis of the study was that the perception of the image of the future of Russia among representatives of generations $\mathrm{X}, \mathrm{Y}$ and $\mathrm{Z}$ differs, first of all, according to such criteria as the attitude to private property, the market economy and the values of the consumer society. The auxiliary hypotheses of the study were the statements that modern Russian society is characterized by a deep moral crisis, as well as that state policy in the socio-cultural sphere is perceived negatively by Russian society as a whole.

Below, we will analyze the respondents' answers to the most revealing questions in terms of assessing the current state of Russian society and its development prospects (table 1).

The answers to this question demonstrate a certain consensus of generations $\mathrm{X}, \mathrm{Y}$ and $\mathrm{Z}$ that Russia is in a state of spiritual crisis and is developing mainly in the direction of borrowing "Western" values. 
Table 1. Results for the responses to the question «How do you assess the current socio-cultural situation in Russia?»

\begin{tabular}{|c|c|c|c|}
\hline & $\begin{array}{l}X \\
\%\end{array}$ & $\begin{array}{l}Y \\
\%\end{array}$ & $\begin{array}{l}Z \\
\%\end{array}$ \\
\hline $\begin{array}{l}\text { Russian society is successfully developing in the direction of the } \\
\text { ideals of morality, spirituality and patriotism }\end{array}$ & 10 & 4.2 & 15 \\
\hline $\begin{array}{l}\text { Russian society, borrowing "Western" values, develops in the } \\
\text { direction of consumer society, individualism and mass culture }\end{array}$ & 38 & 26.8 & 33.9 \\
\hline $\begin{array}{l}\text { Russia is in a state of spiritual and moral crisis, loss of original } \\
\text { culture and national identity }\end{array}$ & 42 & 52.1 & 32.1 \\
\hline $\begin{array}{l}\text { Russia is developing according to the Eurasian scenario, taking } \\
\text { into account the culture and traditions of Europe and Asia }\end{array}$ & 2 & 7 & 5.8 \\
\hline I find it difficult to answer & 4 & 8.5 & 9.9 \\
\hline Other & 4 & 1.4 & 3.3 \\
\hline
\end{tabular}

As a follow-up to the previous question, a question related to the associations that respondents have when referring to the image of modern Russia was asked (table 2).

The options "My Fatherland" and "Native country" were chosen by the vast majority of respondents. This shows the unity in the commitment to their country of representatives of different ages and generations. At the same time, only a very small number of respondents called the Russian state fair, that is, representatives of different generations share the opinion about the unfair nature of the modern Russian state. $16.4 \%$ of representatives of generation $\mathrm{Z}$ called Russia a legal state, as opposed to a very small number of representatives of generations $\mathrm{X}$ and $\mathrm{Y}$. It seems that for generation $\mathrm{Z}$, this characteristic is associated more with a formal constitutional feature than with the true essence of the Russian state. Many respondents agreed on the anti-national characterization of the state, which demonstrates a critical assessment of the official state social policy, independent of the age characteristics of different generations. The greatest agreement in the assessment of Russia was caused by the answer "A state with a rich past and a poor future", it was chosen by almost half of all respondents (table 3 ).

The unanimity of representatives of different generations can be seen in the responses "To develop its own production"; "To implement a fair social policy towards their own people"; "To ensure the rule of law and order in society"; "Need to stop wasting raw materials and internal resources"; "Need to reduce the level of corruption in the state"; "To revive and develop the spiritual and moral ideals of society and national cultural identity." All this shows the commonality of views on the strategic goals of Russia's development of respondents of different ages, brought up in different conditions, but striving for a common goal of forming an economically strong, fair, honest, spiritually developed society. As for the answer "Actively cooperate with the most developed states, even to the detriment of sovereignty", here the answers of representatives of generations $\mathrm{X}$ and $\mathrm{Y}$ are similar, few of them count on external support, but the younger generation somewhat differently assesses the situation, $11.3 \%$ of respondents from generation $\mathrm{Z}$ have hopes for the West.

The answer "We should invest more in digital and nanotechnology" was chosen by almost one in five of the representatives of generation $\mathrm{Z}$. It is obvious that representatives of the younger generation are more willing to support the development of digital technologies than the older generations, since they are largely associated with their ideas about the future of Russia. The development of military power and power institutions as a condition for the revival of the power of the Russian state was chosen by a relatively small

Table 2. Results for the responses to the question «Which of the following phrases do you associate with modern Russia? (specify no more than three)»

\begin{tabular}{|c|c|c|c|}
\hline & $\begin{array}{l}X \\
\%\end{array}$ & $\begin{array}{l}Y \\
\%\end{array}$ & $\begin{array}{l}Z \\
\text { Z }\end{array}$ \\
\hline My Fatherland, My native country & 70 & 76.1 & 77 \\
\hline A just state & 6 & 2.8 & 6.6 \\
\hline A legal state & 4 & 7 & 16.4 \\
\hline Eurasian Civilization & 18 & 7 & 6.6 \\
\hline A totalitarian state & 12 & 22.5 & 19 \\
\hline The anti-people government & 42 & 33.8 & 36.9 \\
\hline A state with a rich past and a poor future & 50 & 47.9 & 47.4 \\
\hline The "Handmaid" of the Western world & 14 & 11.3 & 14.2 \\
\hline I find it difficult to answer & 2 & 4.2 & 8.4 \\
\hline
\end{tabular}


Table 3. Results for the responses to the question «What does Russia need to become a strong state? (specify no more than three)»

\begin{tabular}{|c|c|c|c|}
\hline & $\begin{array}{l}\mathrm{X} \\
\%\end{array}$ & $\begin{array}{l}Y \\
\%\end{array}$ & $\begin{array}{l}\mathrm{Z} \\
\%\end{array}$ \\
\hline Develop its own production & 74 & 57.7 & 43.8 \\
\hline Implement a fair social policy towards their own people & 48 & 53.5 & 66.4 \\
\hline Ensure the rule of law and order in society & 40 & 32.4 & 45.3 \\
\hline $\begin{array}{l}\text { Actively cooperate with the most developed states, even to the } \\
\text { detriment of sovereignty }\end{array}$ & 4 & 5.6 & 11.3 \\
\hline $\begin{array}{l}\text { Return to the policy of a closed state, deal with issues of internal } \\
\text { development, and not gratuitous support for the countries of the } \\
\text { former USSR }\end{array}$ & 16 & 28.2 & 20.1 \\
\hline We need to stop wasting raw materials and internal resources & 36 & 43.7 & 48.5 \\
\hline We should invest more in digital and nanotechnology & 12 & 11.3 & 19.7 \\
\hline To develop the military power and law enforcement institutions & 14 & 5.6 & 8 \\
\hline It is necessary to reduce the level of corruption in the state & 44 & 57.7 & 58 \\
\hline $\begin{array}{l}\text { To revive and develop the spiritual and moral ideals of society } \\
\text { and national and cultural identity }\end{array}$ & 32 & 21.1 & 22.6 \\
\hline I find it difficult to answer & 4 & 1.4 & 3.3 \\
\hline
\end{tabular}

number of young respondents, representatives of the older generation $(\mathrm{X})$, who agree with this statement, almost twice as many. They take external threats more seriously.

The overwhelming majority of respondents agree with the statement that modern Russian society is experiencing a crisis in the moral sphere (table 4).

The similarity in the critical assessment of their own prospects in their country suggests that public opinion as a whole is not satisfied with the direction in which the Russian state is developing, society does not trust state policy and is not confident in the future.

Thus, the data of the empirical study suggest that our hypothesis that the perception of the image of the future of Russia among representatives of different generations is fundamentally different, has not been confirmed (table 5). On the contrary, it is possible to judge the continuity of the main value orientations in Russian society. The auxiliary hypotheses are fully confirmed, since the respondents unanimously recognized the presence of a spiritual and moral crisis in Russian society and generally have a negative attitude to state policy in the socio-cultural sphere.

\section{RESULTS DISCUSSION}

In the macrosociological context, the issues of social design of the future of Russia were raised by such leading Russian sociologists as V.I. Zhukov [8], S.A. Kravchenko [9], A.V. Tikhonov [10], N.V. Romanovsky [11], V.A. Yadov [12], O.N. Yanitsky [13] and others. Along with this, researchers pay attention to the trends in mass consciousness that began to develop in the post-soviet period: anti-historicism, falsification of the past, stereotypes of consumer society, etc. All this forms the attitude of society to social ideals, which, according to their purpose, should act as a reference point that integrates the past, present and future. The image of the future of Russia can be constructed solely on the basis of deep analysis of public opinion about what place does Russia in the past and is today on the world stage, what are the milestones of socio-cultural development of the Russian state influence on the formation of Russia's image and its prospects in achieving optimal, worthy, from the point of view of Russians, the level of development.

The conducted research makes it possible to identify some trends in the perception of social threats and risks that determine the vectors of further development of Russian society by representatives of different

Table 4. Results for the responses to the question «Do you agree with the statement that modern Russian society is experiencing a crisis in the moral sphere?»

\begin{tabular}{|l|c|c|c|}
\hline & $\mathrm{X}$ & $\mathrm{Y}$ & $\mathrm{Z}$ \\
& $\%$ & $\%$ & $\%$ \\
\hline Yes, of course & 52 & 45.2 & 32.5 \\
\hline Rather, yes & 32 & 40.8 & 43.1 \\
\hline Rather, no & 12 & 7 & 10.5 \\
\hline Definitely not & 0 & 1.4 & 5.5 \\
\hline I find it difficult to answer & 4 & 5.6 & 8.4 \\
\hline
\end{tabular}


Table 5. Results for the responses to the question «Is it possible to say that Russian citizens do not have long-term prospects related to their country?»

\begin{tabular}{|l|l|l|l|}
\hline & \multicolumn{1}{|c|}{$\begin{array}{c}\text { X } \\
\%\end{array}$} & \multicolumn{1}{|c|}{$\begin{array}{c}\text { Y } \\
\%\end{array}$} & \multicolumn{1}{c|}{$\begin{array}{l}\text { Z } \\
\text { Yes, of course }\end{array}$} \\
\hline Rather, yes & 36 & 35.2 & 29.6 \\
\hline Rather, no & 32 & 38 & 33.9 \\
\hline Definitely not & 12 & 14.1 & 18.6 \\
\hline I find it difficult to answer & 10 & 2.8 & 5.5 \\
\hline
\end{tabular}

generations. Our ideas are in tune with the works of K.D. Chadaeva [14], who points out that the study of the age dynamics of the structural elements of the image of the future allows us to build a model that determines the specifics of ideas about the future at different ages.

In modern sociological studies of threats to Russian society, scientists pay special attention to: the formation of new social strata (precariates), a new image of society without "mass labour", economic growth and an influential middle class [15]; the problems of excessive income inequality in post-soviet Russia, which leads to the increased social tension [16]; the diversity of social and economic conditions, cultures and subcultures, technological and social structures of various Russian regions, which contribute to the split of Russian society in the need for change or maintaining stability [17]. All these studies are aimed at identifying trends in social development, identifying obstacles to the formation of a decent future for Russia.

Along with the implementation of theoretical research, sociologists regularly conduct empirical research, in which they attempt to form an image of the desired future. The results of sociological surveys and focus groups record the confusion of the population, its uncertainty and fear of the future: "In the mass consciousness, the image of the desired future is in a blurred, amorphous state and is mainly associated with the renaissance of the Soviet past" [18, p.44].

The questions of searching and constructing the image of the future of Russia are important, first of all, in the context of clarifying the features of the mechanism of social identification of the young generation. Depending on how young people set priorities in assessing social threats and risks, in relation to the prospects for the development of Russian society, they to some extent carry out their own identification, being involved in the processes of social interaction.

In our previous publications [19], we have already drawn attention to the fact that, along with socioeconomic and socio-political factors, intra-group and interpersonal interactions have a special impact on the process of socialization and identification of young people, which can also be attributed to the number of social threats, since they tend to have a negative impact on the formation of social identity. Here it is very important to take into account the socio-psychological characteristics of an individual, his/her ability to social activity, the presence of self-consciousness, the ability to resist the negative manifestations of the social environment. Often, the life strategies of young people directly depend on how they are evaluated by society in the face of various social groups. Sometimes negative assessment (stigmatization) on the part of others, as well as self-stigmatization, become a social challenge, which acts as an impulse to search for a new behavioral model that can reveal the promising potential of an individual [20]. All this, in turn, affects the formation of the image of the desired future.

\section{CONCLUSION}

The study suggests that representatives of generations $\mathrm{X}, \mathrm{Y}$, and $\mathrm{Z}$ have a common axiological platform, due to the socio-cultural realities of Russian society. This is reflected in the unanimous positive assessment of Russia as a native Fatherland and a very negative perception of the Russian state and its programs for the strategic development of society.

Despite the fact that almost all respondents were unanimous in their critical attitude to the long-term prospects associated with the country, based on the results of the study, it is possible to judge the presence of the potential of social activity among representatives of different generations in a worthy response to the challenges of our time.

Thus, based on the continuity of Russians of different generations in assessing social risks and threats identified in our study, it is possible to construct a generalized image of the future of Russia: developed own production; careful attitude to national wealth; development of digital and nanotechnologies; fair social policy; the state for the people; legality at all levels of government; a high level of moral development of society; spiritual unity of the Russian people, based on the commonality of the past, present and future. 


\section{AUTHORS' CONTRIBUTION}

Turkulets S.E. - general idea, coordination of interaction of co-authors, organization, conducting and summarizing the results of a sociological survey, preparation of the manuscript of the article.

Turkulets A.V. - the analysis and review of current sources on the topic of research, participation in the preparation of the manuscript of the article.

Listopadova E.V. - participation in the organization and conduct of the survey, analysis of the results of the survey, selection and analysis of relevant foreign literature on the problem, participation in the preparation of the manuscript of the article.

Kalashnikova I.V. - the analysis of the results of the survey, selection and analysis of relevant domestic literature on the problem, participation in the preparation of the manuscript of the article.

\section{FUNDING}

The reported study was funded by RFBR and EISR according to the research project № 20-011-31021.

\section{ACKNOWLEDGMENTS}

Thanks for the help in the preparation of the article are expressed to M.V. Chubiy and I.A. Turkulets.

\section{REFERENCES}

[1] Special Issue: Piketty Symposium, British Journal of Sociology 4 (2014) 589-747.

[2] J. Urry, What is Future? Cambridge, Polity Press, 2016, 214 p.

[3] M.S. Schulz, The Futures We Want. Global Sociology and the Struggles for a Better World, Global Dialogue Vol. 5 Iss. 2 (2015) 7-8.

[4] S.A. Kravchenko, The Future: based on the materials of the Forum of the International Sociological Association Sociological Research 12 (2016) 139-143 (In Russ.).

[5] S.Yu. Demidenko, Russian Society: a Look into the future (materials of the "round table"), Sociological Research 6 (2017) 25-43 (In Russ.).

[6] E.B. Shestopal, A.V. Selezneva, Sociocultural threats and risks in modern Russia, Sociological Research $10 \quad$ (2018) 90-99. DOI: https://doi.org/10.31857/S013216250002161-0 (In Russ.).

[7] S. Turkulets, A. Turkulets and others, Expression of social stigmatization during the pandemic, Journal of Critical Reviews 7(14) (2020) 28372846. DOI: https://doi.org/10.31838/jcr.07.19.540
[8] V.I. Zhukov, Russia in the global system of social coordinates: Sociological Analysis and Forecast, Sociological Research 10 (2008) 29-40; Iss. 12, pp. 3-14 (In Russ.).

[9] S.A. Kravchenko, Sociological theory: Discourse of the Future, Sociological Research 3 (2007) 3-12 (In Russ.).

[10] A.V. Tikhonov, Russian Society as a new social reality and metaproject of Domestic Sociology, Sociological Research 12 (2009) 16-25 (In Russ.).

[11] N.V. Romanovsky, The Future as a problem of Modern Sociology, Sociological Research 11 (2015) 13-22 (In Russ.).

[12] V.A. Yadov, Some sociological grounds for foreseeing the future of Russian society, Russia reforming, ed. by L.M. Drobizheva, Moscow: Academia, 2002, pp. 349-363 (In Russ.).

[13] O.N. Yanitsky, Social restrictions of modernization of Russia, Sociological Research 7 (2010) 17-28 (In Russ.).

[14] K.D. Chadaeva, The image of the future in different ages, Izvestiya Tula State University, Humanities 2 (2013) 294-304 (In Russ.).

[15] V.S. Martyanov, Our rental future: global contours of Society without labor? Sociological Research 5 (2017) 141-153 (In Russ.).

[16] A.E. Varshavsky, Excessive income inequalityproblems and threats for Russia, Sociological Research 8 (2019) 52-61. DOI: https://doi.org/10.31857/S013216250006136-2 (In Russ.).

[17] V.I. Pantin, Russian Society in the early XX and early XXI centuries: Problems and Risk, Sociological Research 11 (2019) 120-130. DOI: https://doi.org/10.31857/S013216250007456-4 (In Russ.).

[18] A.V. Glukhova, O.A. Sidenko, D.V. Sosunov, D.V. Shcheglova, In search of the Desired Future - the Russian Domestic Political Agenda, Sociological Research Vol. 46 Iss. 2 (2020) 46-52. DOI: https://doi.org/10.31857/S013216250008493-5 (In Russ.)

[19] S. Turkulets, E. Listopadova and others, The Process of Stigmatization as a Desocializing Factor, Advances in Social Science, Education and Humanities Research, volume 198, International Conference on the Theory and Practice of Personality Formation in Modern Society (ICTPPFMS-18), Published by Atlantis Press, 
2018, pp. 8-13. DOI:

https://doi.org/10.2991/ictppfms-18.2018.3

[20] S. Turkulets, E. Listopadova and others, Ambivalence of social stigmatization of young people in the Russian Far East, Humanities \& Social Sciences Reviews 7(4) (2019) 433-439. DOI: https://doi.org/10.18510/hssr.2019.7459 